\title{
Chondroblastoma of the Temporal Bone: A Case Series, Review, and Suggested Management Strategy
}

\author{
Luke B. Reid, M.B.B.S. (Hons), Dip.Surg.Anat., ${ }^{1}$ David S. Wong, M.B.B.S., ${ }^{2}$ \\ and Bernard Lyons, F.R.A.C.S. ${ }^{2}$
}

Chondroblastoma of the temporal bone is a rare condition. Chondroblastomas account for less than $1 \%$ of primary bone tumors, and those involving the temporal bone represent a tiny fraction of these tumors with most arising from the knee, rib, and pelvis. We present a case series of two patients who presented with chondroblastomas of the temporal bone over a period of 8 years to the St. Vincent's Hospital in Melbourne, Victoria, Australia. In particular, we outline the presenting complaint, diagnostic imaging undertaken, and the importance of preoperative histopathology in coming to the diagnosis and subsequent resection undertaken. A review of the current literature is presented with a suggested management strategy for these tumors.

KEYWORDS: Chondroblastoma, temporal bone, multidisciplinary, team, management

Chondroblastoma of the temporal bone is a rare condition. ${ }^{1}$ Chondroblastomas account for less than $1 \%$ of primary bone tumors, ${ }^{2}$ and those involving the temporal bone represent a tiny fraction of these tumors with most arising from the knee, rib, and pelvis. ${ }^{2}$

We present a case series of two patients who presented with chondroblastomas of the temporal bone over a period of 8 years to the St. Vincent's Hospital in Melbourne. We will also review the current literature and a suggested management strategy for these tumors.

\section{CASE REPORTS}

\section{Case 1}

A 27-year-old woman with no previous medical history presented with several weeks' history of tinnitus and decreased hearing in the right ear. Physical examination revealed an external auditory canal mass as well as a slight swelling over the right squamous temporal bone region. There were no cranial nerve abnormalities. No formal audiovestibular testing was performed preoperatively.

The computed tomography (CT) and magnetic resonance imaging (MRI) scans demonstrated an aggressive looking destructive mass involving the right petrous temporal bone and temporomandibular joint, centered at the junction between the squamous and petrous temporal bones (Fig. 1A-C). A positron emission tomography (PET) scan revealed the lesion to be intensely metabolically active, in keeping with a malignancy. There was no evidence of metastatic disease on the CT brain/chest/ abdomen/pelvis. Based on the biopsy result of a giant cellrich lesion with pericellular calcification in keeping with a chondroblastoma, the patient underwent a partial tem-

\footnotetext{
${ }^{1}$ Department of Otolaryngology Head and Neck Surgery, Bayside Health, Middle Park, Victoria; ${ }^{2}$ Department of Anatomical Pathology and Otolaryngology Head and Neck, St. Vincent's Hospital, Melbourne, Australia.

Address for correspondence and reprint requests: Luke B. Reid, M.B.B.S. (Hons), Dip.Surg.Anat., Advanced ENT Trainee, Bayside Health, 27 Wright Street, Middle Park, Victoria 3206 (e-mail: drlukereid@hotmail.com).
}

Skull Base Rep 2011;1:71-82. Copyright (C) 2011 by Thieme Medical Publishers, Inc., 333 Seventh Avenue, New York, NY 10001, USA. Tel: +1(212) 584-4662.

Received: August 25, 2010. Accepted after revision: April 12, 2011. Published online: August 4, 2011.

DOI: http://dx.doi.org/10.1055/s-0031-1284217.

ISSN 2157-6971. 
A
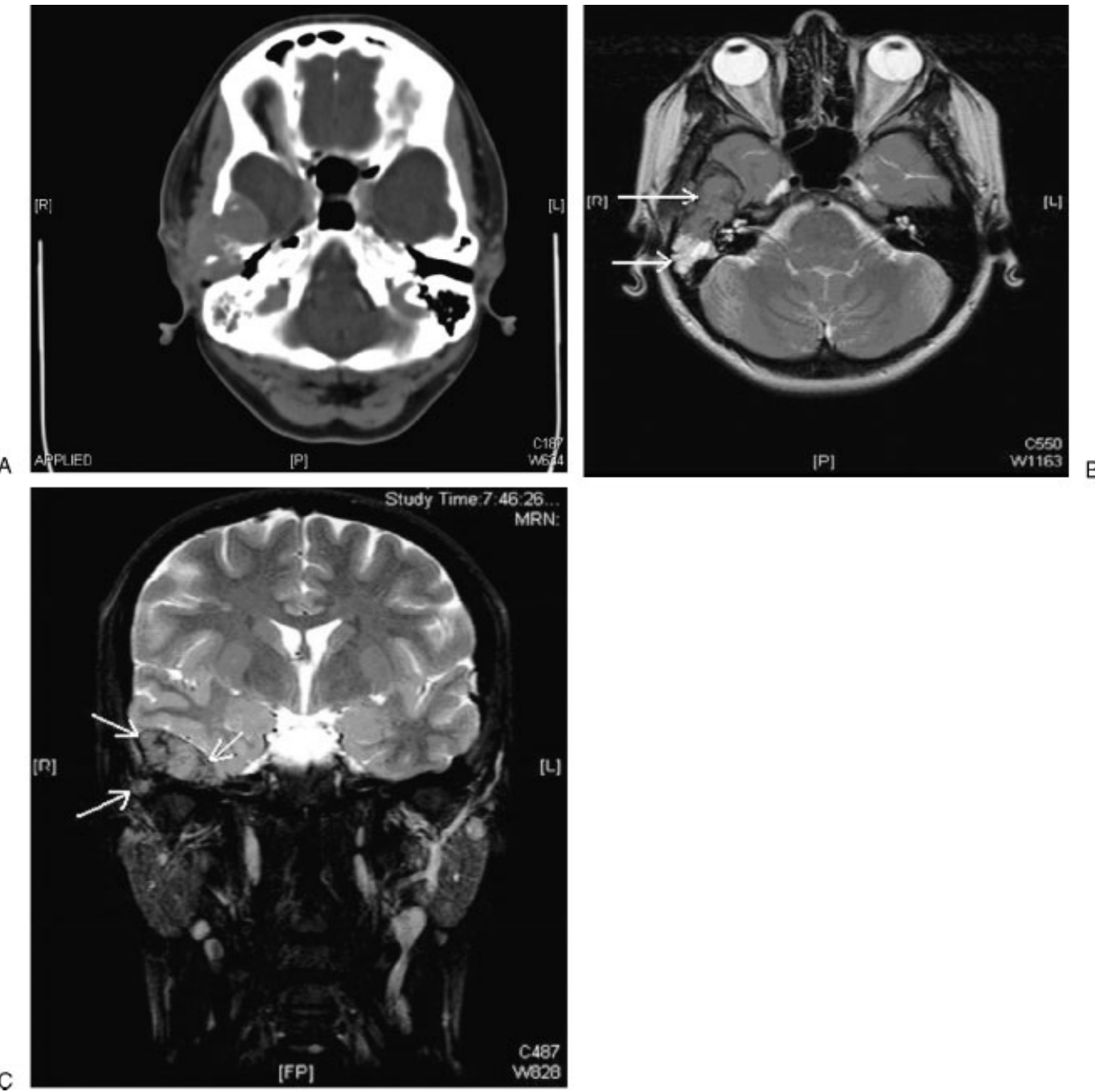

Figure 1 (A) Case 1: Axial CT bone windows. (B) Case 1: Axial T2 MRI. (C) Case 1: T2 Coronal MRI.

poral bone resection, parotidectomy, and mastoid meatoplasty with neurosurgical resection of the middle cranial fossa component. The tumor appeared to be entirely extradural. Of note, the facial nerve was dehiscent in the anterior epitympanum but not involved with tumor. The tumor was dissected free from this area. The patient made a good postoperative recovery.

A complete right facial nerve palsy (HouseBrackmann equivalent 6 [HBe6]) evolved while an inpatient (immediately postoperatively the patient had an HBe2). This complete palsy was present on discharge, but subsequently completely resolved 3 months postoperatively. Definitive histopathology on the resected specimen confirmed a chondroblastoma. Review at 18 months showed no evidence of tumor recurrence and normal facial nerve function.

\section{Case 2}

A 59-year-old woman with a history of type two diabetes mellitus complained of a right pre-auricular swelling that had slowly grown in size over the previous few months. This was associated with localized swelling in the right external auditory meatus, a right-sided facial weakness (HBe2), and mild hearing loss. No formal audiovestibular testing was performed preoperatively; however, free field whisper testing and tuning forks showed only a very small amount of conductive deafness.

The CT and MRI scans showed a lobulated mass in the subcutaneous tissues immediately lateral to the temporomandibular joint, involving the joint and partially encasing the head of the mandible. There was further infiltration into the right external ear canal with a larger soft tissue component in the dorsal aspect of the right zygomatic region (Fig. 2A, B).

The bone scan highlighted scintigraphic uptake within the anteroinferior aspect of the base of the right petrous temporal bone (Fig. 3). A biopsy was consistent with a giant cell tumor of the right temporal bone.

The patient underwent a right infratemporal fossa resection of tumor with partial parotidectomy and temporalis muscle rotation flap and reconstruction of the 


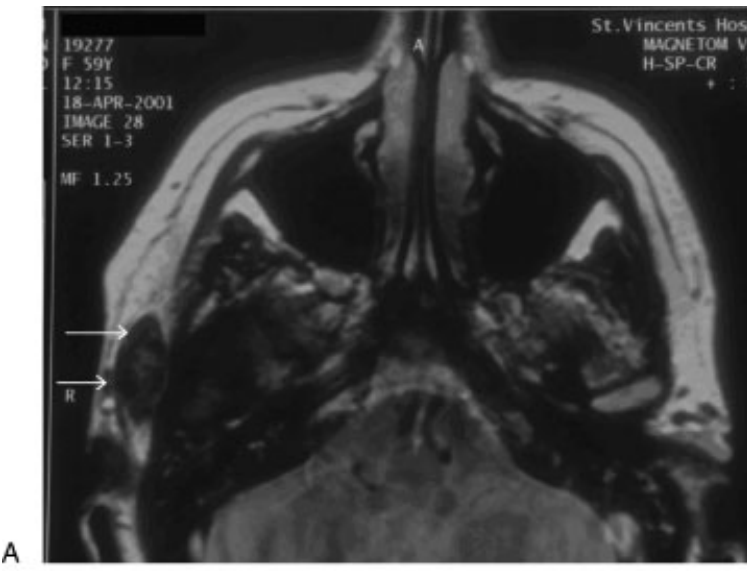

A

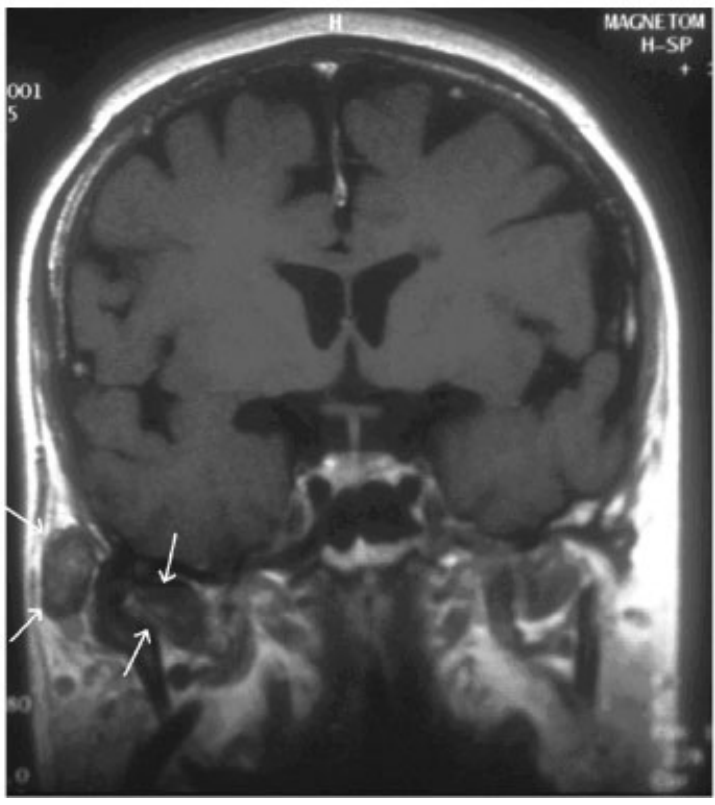

Figure 2 (A) Case 2: MRI Axial. (B) Case 2: MRI Coronal.

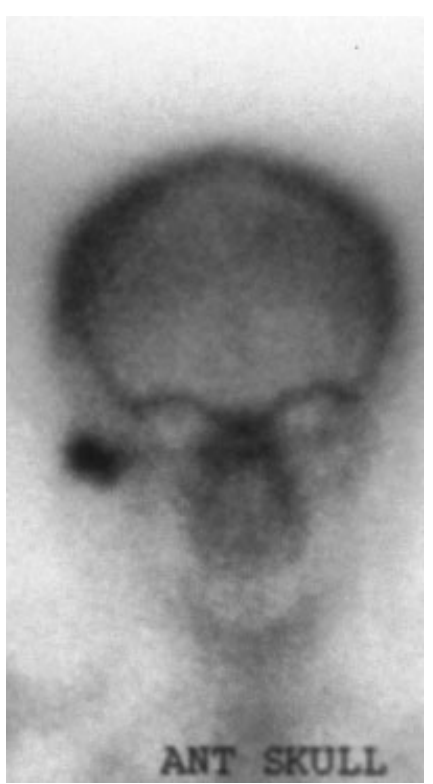

Figure 3 Case 2: Bone scan. right ear canal. The superior division of the facial nerve was found to be associated with the tumor. These branches were dissected free of the tumor and reflected anteriorly. The facial nerve trunk was intact and the inferior division was not involved.

Postoperatively the patient made a good recovery and there was no facial nerve palsy present on discharge. The tumor diagnosis was revised to chondroblastoma on definitive histopathology. Review at 7 years showed no evidence of tumor recurrence.

\section{DISCUSSION}

Chondroblastoma was first described in 1931 by Codman who originally described an "epiphyseal chondromatous giant cell tumor of the proximal humerus," with the diagnosis corrected to chondroblastoma of bone by Jaffe and Lichtenstein in $1942 .^{3}$

The following terms were used in the keywords search tool to do an Ovid Medline literature search with the date parameter 1950 to present:

- Chondroblastoma + skull base

- Chondroblastoma + temporal bone

- Chondroblastoma + diagnosis + temporal bone

- Chondroblastoma + temporal bone + skull base

Only English language journal articles or those translated into English were reviewed. These search strings plus review of the reference lists in the returned articles yielded 41 original articles reporting on a total of 79 cases of chondroblastoma of the temporal bone. Including this current case series, there are total of 81 reported cases worldwide of chondroblastoma of the temporal bone in the English Literature. Table 1 details a summary of those cases presented in the literature. A review of these 81 cases was performed, and an analysis was performed when complete datasets were available.

Of the 73 patients with complete datasets there were 33 females and 40 males affected, giving a slight male predilection with a 1:1.2 female to male ratio.

Average age at presentation for females was 41 years (range, 3 to 85 years, standard deviation of 15.4 years; $n=33$ ) with that for males 41 years (range, 8 to 70 years, standard deviation 15 years; $n=40)$. There was no right to left predilection (right $=30 / 1 \mathrm{eft}=36$ / unknown = 15)

There was considerable variation in the presenting symptoms of chondroblastoma of the temporal bone. Table 2 lists the range of presenting symptoms of chondroblastoma of the temporal bone. The most common presenting symptoms are hearing loss (49\% of reported cases), cranial nerve involvement (43.2\%), facial swelling (22.2\%), and otalgia (19.8\%). A subgroup analysis was performed, but did not yield any useful 


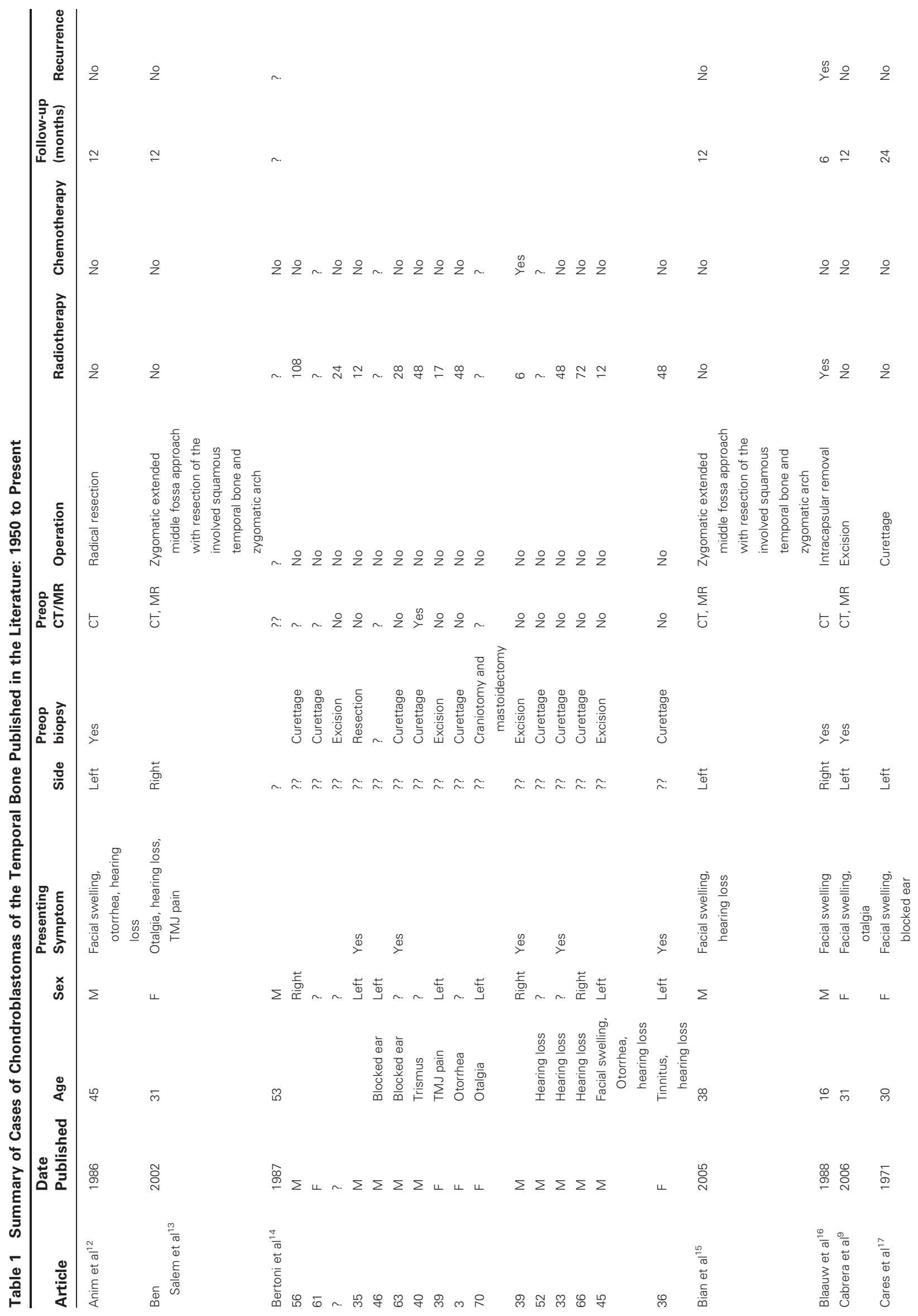




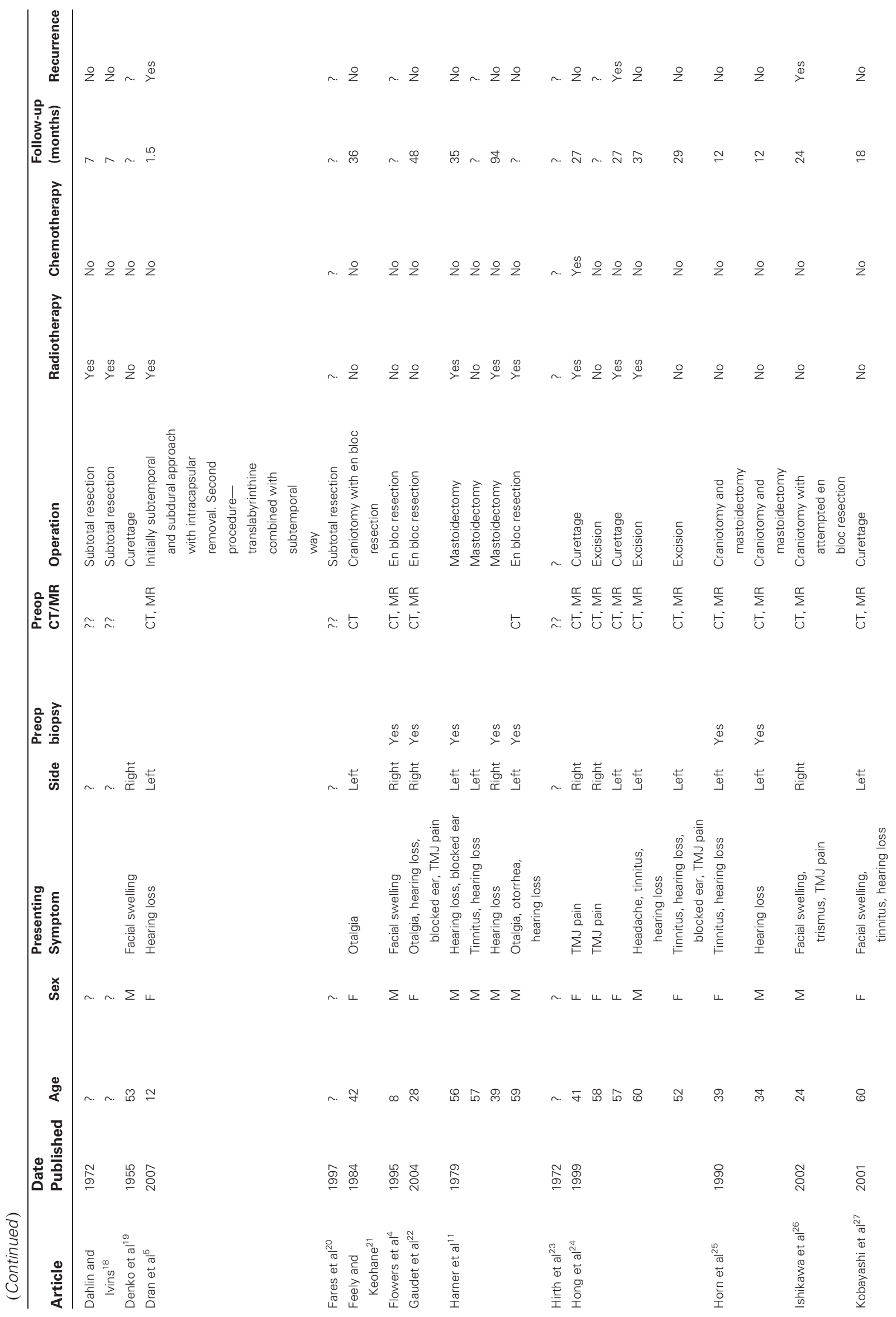




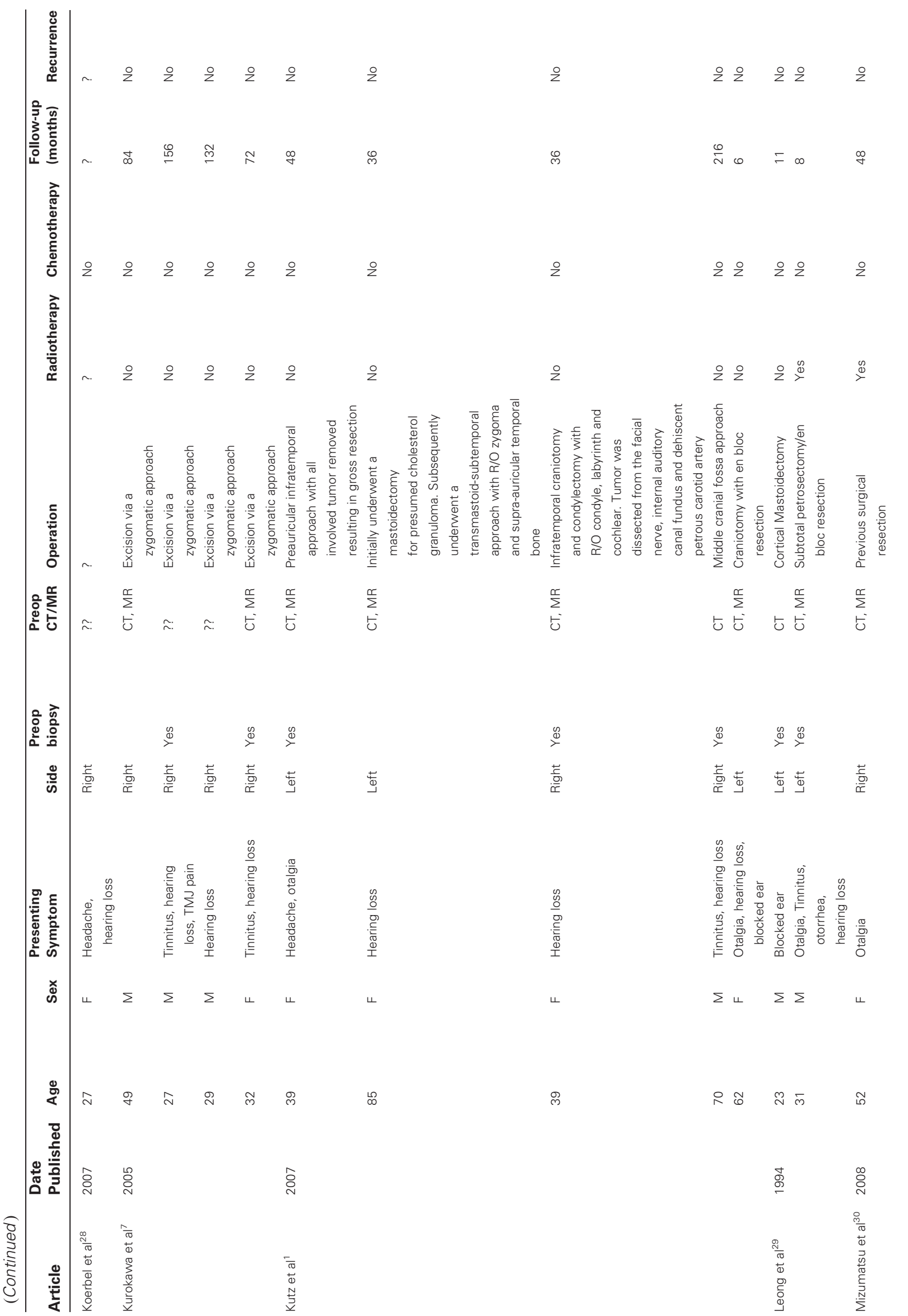




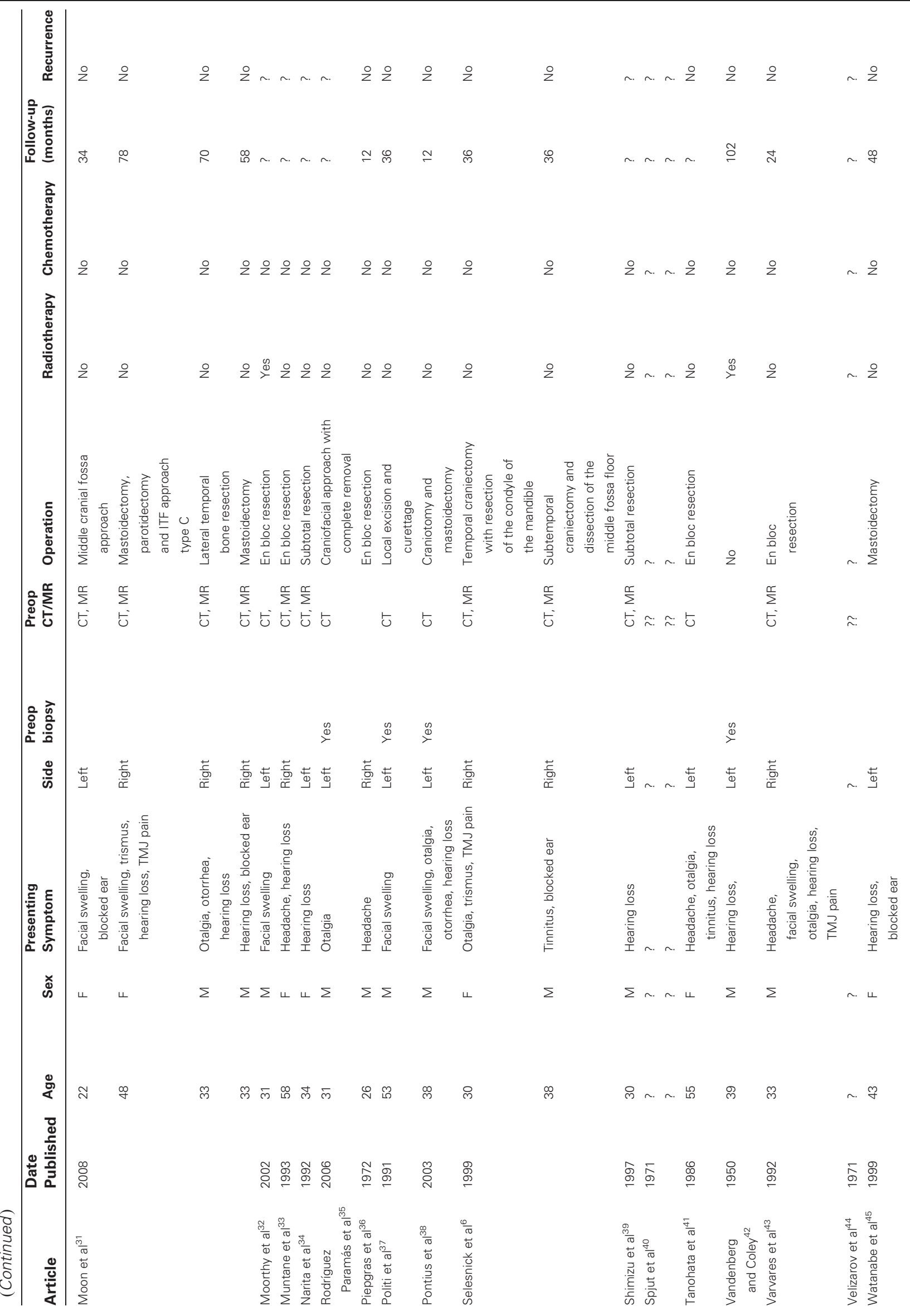




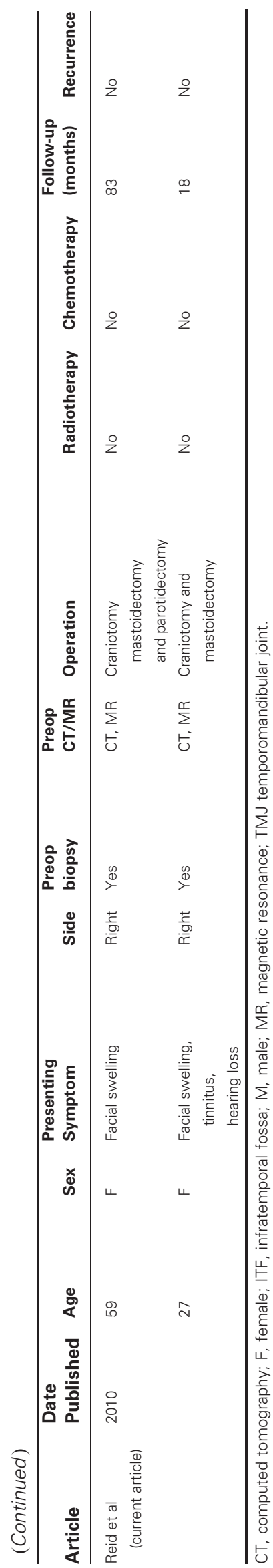

guide regarding a constellation of symptoms typical of this pathology.

The surgical resection of these tumors again showed great heterogeneity in surgical approach. Earlier reports advocated "curettage" for the removal of these tumors, whereas subsequent contemporary articles took a more aggressive approach. Such approaches included "wide local excision," "mastoidectomy with complete/enbloc resection," "craniotomy with en-bloc resection," etc.

Fifteen patients received postoperative radiotherapy, who had had a variety of surgical approaches, with no consistent approach noted. Table 3 lists for those patients who received postoperative radiotherapy the surgical approach undertaken for resection of the chondroblastoma and the number of patients who were treated such. Only one patient received chemoradiotherapy who had undergone "curettage" as the primary procedure.

Average overall follow-up was 52 months with the average time to recurrence being 12.9 months. (Note: This was based on 5 of the 61 cases [8.2\%] with follow-up data.) Table 4 details the cases of recurrence of chondroblastoma. All had undergone subtotal resection of their tumors and three of five had had postoperative radiotherapy.

Radiographic features of chondroblastoma in long bones are characterized by well-defined osteolytic lesions involving the epiphysis or secondary calcification centers. ${ }^{4}$ The diagnosis of chondroblastoma of the temporal bone is aided by imaging using the complementary modalities of CT and MRI. Plain skull X-ray is not helpful in the work-up. (Note: However, the typical findings are of a destructive lytic lesion of the temporal bone. ${ }^{3}$ ) CT imaging typically shows an expansile intraosseous soft tissue mass with internal calcification ${ }^{4}$ and occasional enhancement with intravenous contrast. ${ }^{5}$ Often there is a lytic nature to its growth. ${ }^{6}$ Further, $\mathrm{CT}$ imaging aids in the surgical planning for definitive resection of the tumor as well as defines the underlying bony anatomy. Lastly, it alerts the surgeon to possible intracranial involvement necessitating neurosurgical opinion/involvement in any potential surgical removal.

MRI typically shows a hypo- to intermediate signal on T-1 imaging and high signal on T-2 depending on the chronicity of potential hemorrhages into the mass. ${ }^{4}$ The appearance is that of a heterogeneous mass on T-2 likely due to highly vascular fibrous tissue and intense cellularity. ${ }^{5}$ Postgadolinium enhancement on T2 imaging there is heterogeneity with components of marked hyperintensity. ${ }^{7}$ Lastly, MRI better delineates than CT the extent of intracranial/other soft tissue involvement, importantly that of dura and brain.

The three key diagnostic histopathological findings are the presence of chondroblasts, osteoclastic-like giant cells, and chondromyxoid stroma surrounding neoplastic cells. ${ }^{8}$ Fine needle aspiration (FNA) smears are moderately to markedly cellular and composed of 
Table 2 Presenting Symptoms of Chondroblastoma of the Temporal Bone

\begin{tabular}{ll}
\hline Symptom & $\begin{array}{l}\text { Percentage } \\
\text { of Patients }\end{array}$ \\
\hline Hearing loss & 49.4 \\
Cranial nerve involvement & 43.2 \\
Facial swelling & 22.2 \\
Otalgia & 19.8 \\
Tinnitus & 16.0 \\
Temporomandibular joint pain & 13.6 \\
Blocked ear/aural fullness & 14.8 \\
Pain & 12.3 \\
Headache & 8.6 \\
Otorrhea & 8.6 \\
Trismus & 4.9 \\
\hline
\end{tabular}

osteoclast-type giant cells and mononucleated round to polygonal cells occurring individually or in loose aggregates. 9

Microscopically chondroblastomas are cellular tumors with sheets of mononuclear polyhedral cells admixed with giant cells. ${ }^{7}$ A distinctive microscopic finding is the presence of zones of lacy calcification; "chicken wire" calcification. These tumors express s-100 and vimentin and this s-100 expression differentiates it from a giant cell tumor. ${ }^{7}$ Fig. 4A-F with associated captions further illustrates the histopathological findings. (Fig. 4A-C is from Case 1 and Fig. 4D-F is from Case 2.)

\section{SUGGESTED APPROACH}

Due to the rarity of this tumor there was initially some doubt surrounding the definitive diagnosis. Preoperative imaging with both CT and MRI of the brain and petrous temporal bones with an open biopsy allowed a definitive or a reasonable differential diagnosis before surgery. Multidisciplinary expertise (particularly, confident histopathology input) via multidisciplinary clinics was and is vital in coming to definitive/reasonable diagnoses.

Of the 81 cases reported in the literature, 46 patients underwent a CT of the temporal bone and 35
Table 3 Patients Treated with Postoperative Radiotherapy by Surgical Approach

\begin{tabular}{ll}
\hline Surgical Approach & $\begin{array}{l}\text { Number } \\
\text { of Patients }\end{array}$ \\
\hline Curettage $^{29,46}$ & 3 \\
En bloc resection $^{33}$ & 2 \\
Excision $^{46}$ & 1 \\
Initially subtemporal and subdural $^{\text {approach with intracapsular removal }}$ & 1 \\
Second procedure-translabyrinthine $^{14}$ & \\
$\quad$ combined with subtemporal way $^{14}$ & \\
Intracapsular removal $^{12}$ & 1 \\
Mastoidectomy $^{33}$ & 2 \\
No surgery $^{39}$ & 1 \\
Previous surgical resection $^{16}$ & 1 \\
Subtotal petrosectomy/en bloc resection $^{25}$ & 1 \\
Subtotal resection $^{41}$ & 2 \\
\hline
\end{tabular}

underwent an MRI; all those undergoing MRI also underwent CT. (Note: 27 of the 81 cases had no mention of either preoperative imaging modality.) All cases after 1999, (31 in total) underwent a CT scan as part of their work-up. The same does not hold true for MRI, with reports up to 2007 not imaging their patients with this modality. It is our opinion that the contemporary work-up should include both CT and MRI of the primary site for reasons previously stated.

In the current review, 7 cases underwent FNA and 19 cases underwent open biopsy before definitive surgery and this allowed either a definitive or a reasonably certain diagnosis to be made before surgery. In our current series, the diagnosis of this relative low grade tumor preoperatively (using an open biopsy technique which we recommend) allowed the planning and execution of a more conservative surgical approach than would have been required for a malignant tumor, and thus less morbidity for the patient.

A work-up for metastatic disease, we believe, should be undertaken preoperatively. There is often no mention let alone a standard approach advocated regarding this part of the patient work-up in the current

Table 4 Details of those Cases of Chondroblastoma in the Literature That Had Recurred

\begin{tabular}{|c|c|c|c|}
\hline Initial Surgery & Radiotherapy & Time to Recurrence & Follow-Up Treatment \\
\hline $\begin{array}{l}\text { Craniotomy with attempted } \\
\text { en bloc resection }{ }^{19}\end{array}$ & No & 24 & $\begin{array}{l}\text { Further surgery-3 y follow-up post second } \\
\text { surgery-no recurrence }\end{array}$ \\
\hline Intracapsular removal| ${ }^{12}$ & Yes & 6 & $\begin{array}{l}\text { Mx with curettage and RTx Follow-up } \\
1 \text { y postrecurrence-no abnormality detected }\end{array}$ \\
\hline Excision $^{46}$ & No & 6 & Persistence \\
\hline Curettage $^{46}$ & Yes & 27 & No \\
\hline $\begin{array}{l}\text { Initially subtemporal and subdural } \\
\text { approach with intracapsular removal }\end{array}$ & Yes & 1.5 & $\begin{array}{l}\text { Yes-at } 1.5 \mathrm{mo} \text {; second procedure } \\
\text { attended + RTx - disease-free } 36 \text { mo later }\end{array}$ \\
\hline $\begin{array}{l}\text { Second procedure - translabyrinthine } \\
\text { combined with subtemporal way }{ }^{14}\end{array}$ & & & \\
\hline
\end{tabular}


A
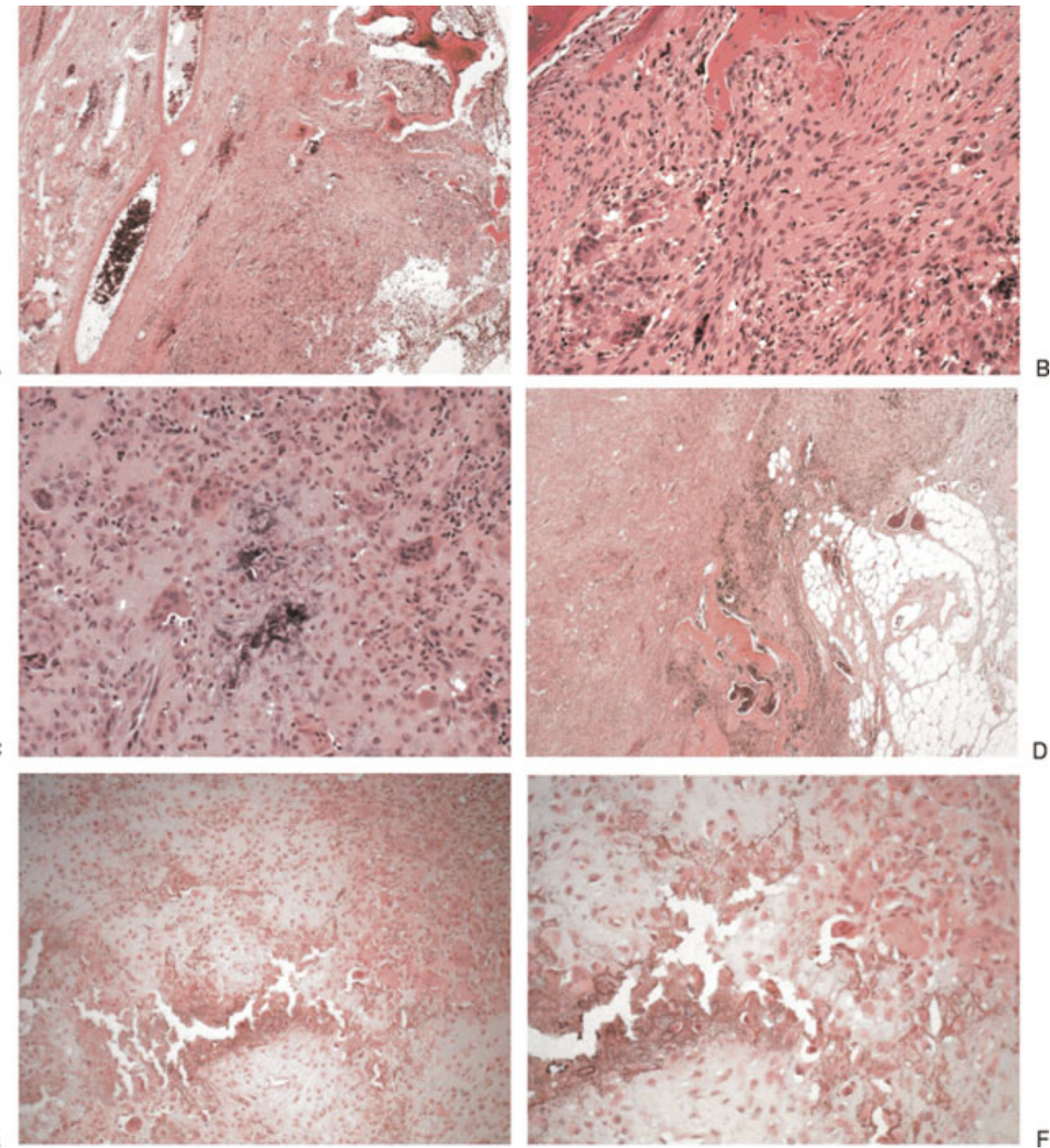

Figure 4 (A) Case 1: A low power H\&E view demonstrating interface of tumor (bottom right) with soft tissue (left) and bone destruction (top right). (B) Case 1: A medium power H\&E view in which there is a cellular tumor composed of plump to spindled cells with admixed osteoclast-like multinucleated giant cells (bottom left). Entrapped trabecular bone is present (top). (C) Case 1: Focally, areas of "chicken-wire" pericellular calcification is a characteristic feature of chondroblastoma. (D) Case 2: In this low power H\&E view there is soft tissue (top right) and bony (mid bottom) infiltration by tumor (left). Hemosiderin pigment is prominent. (E) Case 2: As well as cellular areas with many osteoclast-like giant cells (top right) as seen in the first case, there were also prominent light staining chondroid lobules. (F) Case 2: Higher magnification of the same area in $4 \mathrm{E}$ reveals the "pavimented" array of plump chondroblasts with surrounding pericellular calcification.

literature. Given that pelvic chondroblastoma tumors are known to metastatic to both lung and abdomen, ${ }^{10}$ (sometimes nondefinitive nature of the preoperative diagnosis) imaging should include, in our opinion, CT chest, abdomen, and pelvis. (Note: There are no cases of metastatic disease reported to date.)

Complete but conservative multispecialty surgical excision is the preferred therapeutic option and given that there have been no reported cases of metastatic disease, no adjuvant therapy is warranted.

In this review, heterogeneity of surgical approaches and resections was identified. As mentioned previously, given the low grade nature of this tumor we would advocate a complete but conservative multispecialty surgical resection. In our two cases, we employed either a partial temporal bone resection or an infratemporal fossa resection of tumor with both undergoing partial parotidectomy and facial nerve identification and preservation as part of the approach/resection. Other approaches have been advocated and if they too achieve complete resection of the tumor with a minimum of morbidity then they too can be pursued.

The option of radiotherapy has been described in the literature; however, this was reserved for recurrent 
tumors. ${ }^{11}$ In this current review, the role of radiotherapy is not able to be clearly defined. There is no role for chemotherapy.

Recurrence of these tumors is a possibility, particularly with subtotal resection therefore, long-term follow-up is required. In our series (18 and 78 months postoperative, respectively) no recurrence has occurred.

Lastly, baseline formal audiovestibular function testing should be performed preoperatively in all cases, based on presenting complaint.

\section{CONCLUSION}

Chondroblastoma of the temporal bone is an exceedingly rare tumor with diagnosis based on detailed multimodality imaging techniques, biopsy, and multidisciplinary clinic case review. The tumor is best managed with complete surgical excision. The use of radiotherapy is likely best reserved for recurrent/persistent tumor and long-term follow-up for recurrence is required.

\section{REFERENCES}

1. Kutz JW Jr, Verma S, Tan HT, Lo WW, Slattery WH III, Friedman RA. Surgical management of skull base chondroblastoma. Laryngoscope 2007;117(5):848-853

2. Cotran R, Kumar V, Robbins S. Robbins: Pathological Basis of Disease. 5th ed. Pennsylvania: WB Saunders Company; 1994

3. Spahr J, Elzay RP, Kay S, Frable WJ. Chondroblastoma of the temporomandibular joint arising from articular cartilage: a previously unreported presentation of an uncommon neoplasm. Spahr JElzay RPFrable WJ. Oral Surg Oral Med Oral Pathol 1982;54(4):430-435

4. Flowers CH, Rodriguez J, Naseem M, Reyes MM, Verano AS. MR of benign chondroblastoma of the temporal bone. AJNR Am J Neuroradiol 1995;16(2):414-416

5. Dran G, Niesar E, Vandenbos F, Noel G, Paquis P, Lonjon M. Chondroblastoma of the apex portion of petrousal bone. Childs Nerv Syst 2007;23(2):231-235

6. Selesnick SH, Levine JM. Chondroblastoma of the temporal bone: consistent middle fossa involvement. Skull Base Surg 1999;9(4):301-305

7. Kurokawa R, Uchida K, Kawase T. Surgical treatment of temporal bone chondroblastoma. Surg Neurol 2005;63(3): 265-268; discussion 268

8. Granados R, Martín-Hita A, Rodríguez-Barbero JM, Murillo N. Fine-needle aspiration cytology of chondroblastoma of soft parts: case report and differential diagnosis with other soft tissue tumors. Diagn Cytopathol 2003;28(2):76-81

9. Cabrera RA, Almeida M, Mendonça ME, Frable WJ. Diagnostic pitfalls in fine-needle aspiration cytology of temporomandibular chondroblastoma: report of two cases. Diagn Cytopathol 2006;34(6):424-429

10. Lin PP, Thenappan A, Deavers MT, Lewis VO, Yasko AW. Treatment and prognosis of chondroblastoma. Clin Orthop Relat Res 2005;438:103-109

11. Harner SG, Cody DT, Dahlin DC. Benign chondroblastoma of the temporal bone. Otolaryngol Head Neck Surg 1979; 87(2):229-236
12. Anim JT, Baraka ME. Chondroblastoma of temporal bone: unusual histologic features. Ann Otol Rhinol Laryngol 1986; 95(3 Pt 1):260-263

13. Ben Salem D, Allaoui M, Dumousset E, et al. Chondroblastoma of the temporal bone associated with a persistent hypoglossal artery. Acta Neurochir (Wien) 2002;144(12): 1315-1318

14. Bertoni F, Unni KK, Beabout JW, Harner SG, Dahlin DC. Chondroblastoma of the skull and facial bones. Am J Clin Pathol 1987;88(1):1-9

15. Bian LG, Sun QF, Zhao WG, Shen JK, Tirakotai W, Bertalanffy H. Temporal bone chondroblastoma: a review. Neuropathology 2005;25(2):159-164

16. Blaauw G, Prick JJ, Versteege C. Chondroblastoma of the temporal bone. Neurosurgery 1988;22(6 Pt 1):1102-1107

17. Cares HL, Terplan K. Chondroblastoma of the skull. Case report. J Neurosurg 1971;35(5):614-618

18. Dahlin DC, Ivins JC. Benign chondroblastoma. A study of 125 cases. Cancer 1972;30(2):401-413

19. Denko JV, Krauel LH. Benign chondroblastoma of bone; an unusual localization in temporal bone. AMA Arch Pathol 1955;59(6):710-711

20. Fares G, Aïdan P, Bouccara D, Molas G, Gomulinski L, Sterkers O. [Chondroblastoma of the temporal bone. Apropos of a case]. Ann Otolaryngol Chir Cervicofac 1997;114(4): 130-133

21. Feely M, Keohane C. Chondroblastoma of the temporal bone case report and literature review. Ann Otol Rhinol Laryngol 1992;101:764-769

22. Gaudet EL Jr, Nuss DW, Johnson DH Jr, Miranne LS Jr. Chondroblastoma of the temporal bone involving the temporomandibular joint, mandibular condyle, and middle cranial fossa: case report and review of the literature. Cranio 2004;22(2):160-168

23. Hirth R, Städtler F, Piepgras U. [An intracranial chondroblastoma]. Arch Psychiatr Nervenkr 1972;216(4):359-369

24. Hong SM, Park YK, Ro JY. Chondroblastoma of the temporal bone: a clinicopathologic study of five cases. J Korean Med Sci 1999;14(5):559-564

25. Horn KL, Hankinson H, Nagel B, Erasmus M. Surgical management of chondroblastoma of the temporal bone. Otolaryngol Head Neck Surg 1990;102(3):264-269

26. Ishikawa E, Tsuboi K, Onizawa K, et al. Chondroblastoma of the temporal base with high mitotic activity. Neurol Med Chir (Tokyo) 2002;42(11):516-520

27. Kobayashi Y, Murakami R, Toba M, et al. Chondroblastoma of the temporal bone. Skeletal Radiol 2001;30(12):714-718

28. Koerbel A, Loewenheim H, Beschorner R, et al. Surgical treatment and outcomes of temporal bone chondroblastoma. Eur Arch Otorhinolaryngol 2008;265:1447-1454

29. Leong HK, Chong PY, Sinniah R. Temporal bone chondroblastoma: big and small. J Laryngol Otol 1994;108(12):11151119

30. Mizumatsu S, Sakai K, Nishimura T, et al. [Gamma knife radiosurgery for temporal bone chondroblastoma: case report]. No Shinkei Geka 2008;36(1):65-69

31. Moon IS, Kim J, Lee HK, Lee WS. Surgical treatment and outcomes of temporal bone chondroblastoma. Eur Arch Otorhinolaryngol 2008;265(12):1447-1454

32. Moorthy RK, Daniel RT, Rajshekhar V, Chacko G. Skull base chondroblastoma: a case report. Neurol India 2002; 50(4):534-536 
33. Muntané A, Valls C, Angeles de Miquel MA, Pons LC. Chondroblastoma of the temporal bone: $\mathrm{CT}$ and MR appearance. AJNR Am J Neuroradiol 1993;14(1): $70-71$

34. Narita Y, Morimoto T, Nishikawa R, et al. [Chondroblastoma of the temporal bone-report of a case and a review of the literature of 54 cases]. No To Shinkei 1992;44(2): 143-148

35. Rodríguez Paramás A, Lendoiro Otero C, González García JA, Souviron Encabo R, Scola Yurrita B. [Temporal bone chondroblastoma. A clinical case and literature review]. Acta Otorrinolaringol Esp 2006;57(7):336-338

36. Piepgras U, Hirth R, Städtler F, Kammerer V. Chondroblastoma of the temporal bone, an unusual cause of increasing intracranial pressure. Neuroradiology 1972;4(1):25-29

37. Politi M, Consolo U, Panziera G, Capelli P, Bonetti F. Chondroblastoma of the temporal bone. Case report. J Craniomaxillofac Surg 1991;19(7):319-322

38. Pontius A, Reder P, Ducic Y. Diagnostic pitfalls in fine needle aspiration cytology of temporomandibular chondroblastoma: report of two cases. Diagn Cytopathol 2006;34(6): 424-429
39. Shimizu J, Kaito N, Akiba Y, et al. [Chondroblastoma of the temporal bone: a case report]. No Shinkei Geka 1997;25(6): 555-559

40. Spjut HJ, Dorfmen HD, Fechner RE, Ackerman LV. Gamma Knife radiosurgery for temporal bone chondroblastoma: case report. No Shinkei Geka 2008;36(1):65-69

41. Tanohata K, Noda M, Katoh H, et al. Chondroblastoma of temporal bone. Neuroradiology 1986;28(4):367-370

42. Vandenberg HJ, Coley BL. Chondroblastoma of the temporal bone: a case report. No Shinkei Geka 1950;25(6):555-559

43. Varvares MA, Cheney ML, Goodman ML, Ceisler E, Montgomery WW. Chondroblastoma of the temporal bone. Case report and literature review. Ann Otol Rhinol Laryngol 1992;101(9):763-769

44. Velizarov A, Lolova I, Hristov V. Rare localization of chondroblastoma. Nauchni Tr Vissh Med Inst Sofiia 1971; 50(2):39-46

45. Watanabe N, Yoshida K, Shigemi H, Kurono Y, Mogi G. Temporal bone chondroblastoma. Otolaryngol Head Neck Surg 1999;121(3):327-330

46. Hong SM, Park YK, Ro JY. Primary tumors of the cranial bones, surgery. Gynecol Obstet (Paris) 1950;90:602-612 